\title{
TOLERÂNCIA DO FEIJÃO-CAUPI A DIFERENTES HERBICIDAS APLICADOS EM PÓS-EMERGÊNCIA
}

\author{
Ruan Medeiros Cavalcante ${ }^{1}$, Rommel Santos Siqueira Gomes ${ }^{2}$, Gilmar Silva Nunes ${ }^{2}$, Túlio Gondim Alves ${ }^{1}$, \\ Renato Francisco da Silva Souza ${ }^{3}$, Severino Pereira Souza Júnior ${ }^{1}$ \\ ${ }^{1}$ Universidade Federal da Paraíba - UFPB, Centro de Ciências Agrárias, Areia, Brasil. ${ }^{2}$ Universidade Federal da Paraíba - \\ UFPB, Programa de Pós-graduação em Agronomia, Areia, Brasil. ${ }^{3}$ Universidade Federal da Paraíba - UFPB, Programa de \\ Pós-graduação em Ciência do Solo, Areia, Brasil. E-mail: pratacca@gmail.com
}

\section{RESUMO}

Um dos entraves à produção de feijão-caupi é a intensidade de infestações de plantas daninhas que podem interferir na sua produtividade. $\mathrm{O}$ uso de herbicidas é tido como a estratégia de controle mais eficiente, pelas respostas satisfatórias, rápidas e facilidade de aplicação. O objetivo do trabalho foi avaliar a tolerância do feijão-caupi, cultivar BRS Guariba, aos herbicidas Linurom e Quizalofope-P-etílico, na fase inicial de desenvolvimento da cultura. $O$ experimento foi conduzido em regime de sequeiro, com irrigação de salvação, sob condições de campo, em delineamento experimental com blocos ao acaso, nove tratamentos e quatro repetições. Os tratamentos avaliados foram: $50 \%$ de Quizalofope-P-etílico; $50 \%$ de Linurom; 100\% de Quizalofope-P-etílico; 100\% de Linurom; 50\% de Quizalofope-P-etílico + 50\% de Linurom; 50\% de Quizalofope-P-etílico + 100\% de Linurom; 100\% de Quizalofope-P-etílico + 50\% de Linurom; 100\% de Quizalofope-P-etílico $+100 \%$ de Linurom e Capina manual (testemunha). Foram realizadas avaliações visuais de controle de plantas daninhas, fitotoxidez, altura de planta, número de folhas e diâmetro do caule. As plantas de feijão-caupi, cultivar BRS Guariba, apresentam elevada tolerância aos herbicidas Quizalofope-P-etílico e Linurom à 50\% em aplicações pós-emergência. O herbicida Linurom à $100 \%$ e a formulação do Quizalofope-P-etílico + Linurom provocam danos severos ao desenvolvimento da cultura do feijão-caupi. A mistura entre os herbicidas à 100\% de Quizalofope-P-etílico e $100 \%$ de Linurom potencializa o efeito dos herbicidas sobre a cultura da feijão-caupi, ocasionando a morte das plantas.

Palavras-chave: controle químico; fitotoxidez; plantas daninhas; Vigna unguiculata L. Walp.

\section{TOLERANCE OF COWPEA TO DIFFERENT HERBICIDES APPLIED IN POST-EMERGENCE}

\begin{abstract}
One of the obstacles to the production of cowpea is the intensity of weed infestations that may interfere with its productivity. The objective of this work was to evaluate the tolerance of cowpea, cultivar BRS Guariba, to the herbicides Linurom and Quizalofope-P Etílico, in the initial stage of development of the crop. The experiment was conducted in sequestration system, emergency irrigation under field conditions in experimental design with randomized blocks, nine treatments and four replicates. The treatments evaluated were: 50\% Quizalofope-P-Ethyl; 50\% of Linurom; 100\% Quizalofope-P-Ethyl; $100 \%$ of Linurom; 50\% Quizalofope-P-Ethyl + 50\% Linurom; 50\% Quizalofope-P-Ethyl + 100\% Linurom; 100\% Quizalofope-PEthyl $+50 \%$ Linurom; $100 \%$ of Quizalofope-P-Ethyl $+100 \%$ of Linurom, and Manual weeding (control). Visual evaluations of weed control, phytotoxicity, plant height, number of leaves and stem diameter were performed. The cowpea plants, BRS Guariba cultivar, presented high tolerance to the herbicides $50 \%$ and $50 \%$ in the post-emergence applications. The herbicide $100 \%$ Linurom and the formulation of the Quizalofope-P-Ethyl + Linurom cause severe damage to the development of cowpea. The herbicides blended with $100 \%$ of Quizalofope-P-Ethyl and $100 \%$ of Linurom potentiates the effect of the herbicides on the cowpea crop, causing the death of the plants.
\end{abstract}

Keywords: chemical control; phytotoxitcy; weeds; Vigna unguiculata L. Walp. 


\section{INTRODUÇÃO}

O feijão-caupi, conhecido também por feijão-macassar ou feijão-de-corda, é um alimento de alto valor nutritivo, rico em proteínas, carboidratos, fibras e minerais (FROTA et al., 2008). Essa espécie é cultivada nas regiões tropicais e subtropicais do mundo. No Brasil, principalmente nas regiões Norte e Nordeste, ela se constitui em uma das principais alternativas sociais e econômicas para as populações rurais (OLIVEIRA et al., 2011).

O feijão-caupi apresenta ciclo relativamente curto, entre 60 e 80 dias e desenvolve-se bem em condições de pouca disponibilidade hídrica e baixa fertilidade do solo. Entretanto, seu cultivo tem-se expandido em larga escala na região centro-oeste e tem sido conduzido, especialmente, após a cultura da soja, como segunda safra ou safrinha (EMBRAPA, 2002; CASTELLETTI; COSTA, 2013).

Dentre os diversos fatores que afetam a cultura do feijão-caupi, destaca-se a interferência exercida pelas plantas daninhas, pois competem por luz, nutrientes e água, refletindo diretamente na redução quantitativa e qualitativa da produção. Além disso, aumenta os custos operacionais de colheita, secagem, beneficiamento dos grãos e, quando não controladas, podem reduzir o rendimento de grãos em até 90\% (FREITAS et al., 2009).

A estratégia de controle de plantas daninhas mais utilizada no feijão-caupi é a capina manual, por se tratar de uma cultura explorada principalmente no sistema de agricultura familiar (FREIRE FILHO, 2011). Entretanto, em áreas extensas, o alto custo da mão-de-obra e a dificuldade de encontrar operários em quantidade suficiente, fazem com que este método seja apenas complementar aos demais (FREITAS et al., 2009).

O controle de plantas daninhas por meio da aplicação de herbicidas vem sendo amplamente empregado em diversas culturas anuais, seja isoladamente ou na forma de misturas. Todavia, há falta de produtos químicos registrados junto ao Ministério da Agricultura Pecuária e Abastecimento, o que impede a recomendação e o uso de tais produtos no campo, bem como impede o conhecimento sobre sua ação sobre plantas não-alvo (SILVA; ALBERTINO, 2009).

Estudos recentes conduzidos por Mancuso et al. (2016) e Mesquita et al. (2017) avaliaram a seletividade e eficiência de herbicidas no controle de plantas daninhas na cultura do feijão-caupi. No entanto, ainda se conhece pouco sobre a seletividade de herbicidas a cultura, sendo necessário o estudo do efeito de mais moléculas herbicidas sobre a planta, de maneira a buscar opções que proporcionem controle mais eficiente das plantas daninhas e menor efeito fitotóxico sobre a cultura (SILVA et al., 2016).

Diante do exposto, o objetivo desse trabalho foi avaliar a tolerância do feijão-caupi, cultivar BRS Guariba, aos herbicidas Linurom e Quizalofope-P Etílico, na fase inicial de desenvolvimento da cultura.

\section{MATERIAL E MÉTODOS}

$O$ experimento foi conduzido em regime de sequeiro, com irrigação de salvação, sob condições de campo entre maio a junho de 2017 em área experimental localizada em latitude $6^{\circ} 58^{\prime} 12^{\prime \prime} \mathrm{S}$ e longitude $35^{\circ} 45^{\prime} 15^{\prime \prime} \mathrm{O}$ a uma altitude de $575 \mathrm{~m}$, Areia (PB). De acordo com a classificação climática de Gaussen, o bioclima predominante na área é o 3dth nordestino subseco, com precipitação pluviométrica média anual de $1400 \mathrm{~mm}$, já o clima é o tipo As', caracterizado como quente e úmido, com chuvas de outono-inverno pela classificação de Köppen. Quanto a temperatura média oscila entre 21 e 26 ${ }^{\circ} \mathrm{C}$, com variações mensais mínimas.

A análise de caracterização química do solo apresentou os seguintes resultados: $\mathrm{pH}$ (água) $=5,6 ; \mathrm{MO}=21,33 \mathrm{~g} \mathrm{~kg}^{-1}, \mathrm{P}=27,39 \mathrm{mg} \mathrm{dm}$ $3, \mathrm{~K}^{+}=39,97 \mathrm{cmol}_{\mathrm{c}} \mathrm{dm}^{-3}, \mathrm{Ca}^{2+}=3,18 \mathrm{cmol}_{\mathrm{c}} \mathrm{dm}^{-3}$, $\mathrm{Na}^{+}=0,17 \mathrm{cmol}_{\mathrm{c}} \mathrm{dm}^{-3}$ e $\mathrm{Mg}^{2+}=1,09 \mathrm{cmol}_{\mathrm{c}} \mathrm{dm}^{-3}$, com classe textural de solo argilosa. Em seguida foi realizado o preparo do solo conforme sistema convencional, com aração e gradagem (CORRÊA et al., 2016). A adubação de plantio foi feita com base na análise de fertilidade do solo, em que foram utilizados $200 \mathrm{~kg} \mathrm{ha}^{-1}$ da formulação 6-2412 (N-P-K).

A semeadura foi realizada manualmente com sementes de feijão-caupi, cultivar BRS Guariba, caracterizada pelo porte semiereto, grãos brancos, com ciclo em torno de 61 a 70 de dias (VILARINHO, 2007) com densidade de 10 plantas por metro linear. $O$ delineamento experimental utilizado foi em blocos ao acaso com nove tratamentos (Tabela 1 ) e quatro repetições. Cada parcela experimental foi constituída de quatro fileiras de $1 \times 1,5 \mathrm{~m}$, espaçadas de $0,5 \mathrm{~m}$ entre si. A área útil de cada parcela foi composta pelas duas fileiras centrais, descartando-se $0,5 \mathrm{~m}$ em cada uma das 
extremidades (bordaduras). Os blocos foram espaçados em 1,0 $\mathrm{m}$, para uma melhor locomoção.

Tabela 1. Tratamentos à base de herbicidas utilizados no controle de plantas daninhas em cultivo de feijão-caupi (Vigna unguiculata L. Walp.). Areia (PB)

\begin{tabular}{cllcc}
\hline Tratamentos & \multicolumn{1}{c}{ Nome comercial } & \multicolumn{1}{c}{ Ingrediente ativo } & $\%$ & $\begin{array}{c}\text { Dose usada (g i.a } \\
\left.\text { ha }^{-1}\right)^{*}\end{array}$ \\
\hline T1 & Targa EC 50 & Quizalofope-P Etílico & 50 & 0,6 \\
\hline T2 & Afalon SC 450 & Linurom & 50 & 1,2 \\
\hline T3 & Targa EC 50 & Quizalofope-P Etílico & 100 & 1,2 \\
\hline T4 & Afalon SC 450 & Linurom & 100 & 2,4 \\
\hline T5 & $\begin{array}{l}\text { Targa EC 50 + Afalon } \\
\text { SC 450 }\end{array}$ & $\begin{array}{l}\text { Quizalofope-P Etílico + } \\
\text { Linurom }\end{array}$ & $50+50$ & $1,2+0,6$ \\
\hline T6 & $\begin{array}{l}\text { Targa EC 50 + Afalon } \\
\text { SC 450 }\end{array}$ & $\begin{array}{l}\text { Quizalofope-P Etílico + } \\
\text { Linurom }\end{array}$ & $50+100$ & $1,2+1,2$ \\
\hline T7 & $\begin{array}{l}\text { Targa EC 50 + Afalon } \\
\text { SC 450 }\end{array}$ & $\begin{array}{l}\text { Quizalofope-P Etílico } \\
\text { +Linurom }\end{array}$ & $100+50$ & $2,4+0,6$ \\
\hline T8 & $\begin{array}{l}\text { Targa EC 50 + Afalon } \\
\text { SC 450 }\end{array}$ & $\begin{array}{l}\text { Quizalofope-P Etílico + } \\
\text { Linurom }\end{array}$ & $100+100$ & $2,4+1,2$ \\
\hline T9 & Testemunha & Capina manual & ---- & -- \\
\hline
\end{tabular}

A aplicação dos tratamentos ocorreu aos 30 dias após a semeadura (DAS) do feijãocaupi. Foi utilizado um pulverizador manual costal com pressão constante de $150 \mathrm{kPa}$, equipado com bicos contendo ponta tipo leque modelo TT-11002, a uma altura de $50 \mathrm{~cm}$ do alvo, com velocidade de $1 \mathrm{~m} \mathrm{~s}^{-1}$, e volume de calda de $180 \mathrm{~L} \mathrm{ha}^{-1}$.

As avaliações de altura da planta e diâmetro do caule, foram mensuradas com auxílio de uma régua milimetrada e paquímetro e, feito a contagem do número de folhas aos 7 , 14, 21 e 28 dias após aplicação dos herbicidas (DAAH). Essas variáveis resultaram das médias das três plantas presentes em cada parcela útil.

Foram feitas avaliações visuais de controle de plantas daninhas e fitotoxidez sobre as plantas não-alvo as $28 \mathrm{DAAH}$, com a utilização da escala visual proposta pela European Weed Research Council - EWRC (SIZENANDO FILHO et al., 2013) (Tabela 2).

Tabela 2. Escala de notas para determinação da fitotoxidez de herbicidas à cultura do feijãocaupi (Vigna unguiculta L. Walp.) e do nível de controle das plantas daninhas. Areia (PB)

\begin{tabular}{c|l|cl}
\hline & \multicolumn{1}{|c|}{ Cultura } & \multicolumn{2}{c}{ Planta daninha } \\
\hline Nota & \multicolumn{1}{|c}{ Nitotoxidez } & Nota & \multicolumn{2}{c}{ Controle } \\
\hline 1 & Nula & 2 & Necrose total \\
\hline 2 & Muito leve & 3 & Forte \\
\hline 3 & Leve & 4 & Quase forte \\
\hline 4 & Sem influência na produção & 5 & Média \\
\hline 5 & Média & 6 & Sem influência na produção \\
\hline 6 & Quase forte & 7 & Leve \\
\hline 7 & Forte & 8 & Muito leve \\
\hline 8 & Muito forte & 9 & Nula \\
\hline 9 & Necrose total & &
\end{tabular}

*Adaptado de Weed Research Council (EWRC, 1964)

Para as variáveis analisadas de altura da planta, diâmetro do caule e número de folhas, a análise estatística foi adotada o esquema em parcelas subdivididas, considerando os 
tratamentos (herbicidas) como fator primário, e o tempo como fator secundário. Posteriormente foram submetidos à análise de variância e as médias quando significativas foram agrupadas segundo critério de Scott-Knott, a 5\% de probabilidade de erro no programa estatístico ASSISTAT ${ }^{\circ}$ versão 7.7 beta (SILVA, 2012).

\section{RESULTADOS E DISCUSSÃO}

Quanto aos valores referentes à altura de plantas, ocorreu diferença estatística $(p<0,001)$ entre tratamentos versos períodos de avaliação (Tabela 3), verificando-se o maior valor de altura de plantas para o tratamento T2, sobressaiu em relação aos demais tratamentos aos 28 dias após aplicação dos herbicidas.

Tabela 3. Altura de plantas $(\mathrm{cm})$ de feijão-caupi (Vigna unguiculata L. Walp.), após aplicação de herbicidas (DAAH). Areia (PB), 2017

\begin{tabular}{cccccc}
\hline \multirow{2}{*}{ Tratamentos } & \multicolumn{4}{c}{ Períodos de avaliação } \\
\cline { 2 - 5 } & T1 & 7 DAAH & 14 DAAH & 21 DAAH & 28 DAAH \\
\hline & T2 & $39,58 \mathrm{aA}$ & $46,33 \mathrm{aA}$ & $48,50 \mathrm{aA}$ & $50,33 \mathrm{aA}$ \\
& $38,42 \mathrm{aA}$ & $46,04 \mathrm{aA}$ & $50,17 \mathrm{aA}$ & $50,67 \mathrm{aA}$ \\
& T3 & $26,00 \mathrm{aA}$ & $28,92 \mathrm{bA}$ & $30,17 \mathrm{bA}$ & $29,92 \mathrm{bA}$ \\
& T4 & $35,25 \mathrm{aA}$ & $42,83 \mathrm{aA}$ & $43,83 \mathrm{aA}$ & $49,92 \mathrm{aA}$ \\
& T5 & $14,92 \mathrm{bA}$ & $18,50 \mathrm{bA}$ & $18,33 \mathrm{bA}$ & $23,33 \mathrm{bA}$ \\
& T6 & $16,00 \mathrm{bA}$ & $18,00 \mathrm{bA}$ & $21,00 \mathrm{bA}$ & $21,68 \mathrm{bA}$ \\
& T7 & $16,83 \mathrm{bA}$ & $21,18 \mathrm{bA}$ & $21,17 \mathrm{bA}$ & $22,68 \mathrm{bA}$ \\
& T8 & ----- & ----- & ---- & --- \\
\hline & T9 & $37,67 \mathrm{aA}$ & $48,08 \mathrm{aA}$ & $52,00 \mathrm{aA}$ & $53,92 \mathrm{aA}$ \\
\hline
\end{tabular}

Médias seguidas de mesma letra minúscula na coluna e maiúscula na linha não se diferenciam estatisticamente pelo teste de Scott-Knott a 5\% de probabilidade. T1=50\% Quizalofope-P-Etílico; T2=50\% Linurom; T3=100 Quizalofope-PEtílico; T4=100\% Linurom; T5=50\% Quizalofope-P-Etílico + 50\% Linurom; T6=50\% Quizalofope-P-Etílico + 100\% Linurom; T7= 100\% Quizalofope-P-Etílico + 50\% Linurom; T8=100\% Quizalofope-P-Etílico + 100\% Linurom e T9= Capina manual.

Não foi possível avaliar a altura de planta (Tabela 3) no tratamento com Quizalofope-P Etílico + Linurom (100+100 \%), uma vez que este produto não permitiu 0 crescimento das plantas e com isso não foi possível realizar a observação desse parâmetro. O herbicida Quizalofope-P-etílico é um graminicida seletivo recomendado para a cultura do feijoeiro (Phaseolus vulgaris L.) para o controle de plantas daninhas em pós-emergência (COBUCCl; WRUCK, 2005). Contudo, ao ser utilizada uma mistura com Linurom em sua dosagem máxima de $100 \%$, afetou consideravelmente o desenvolvimento do feijãocaupi, o qual provocou a morte da planta (Tabela 3). Segundo Correa et al. (2008) este fato pode variar de acordo com a planta não alvo e com os ingredientes ativos dos herbicidas usados, como foi observado em plantas de soja (Glycine max L.), que não sofreram danos na sua altura ou número de folhas quando foram aplicados os herbicidas Roundup Ready, Classic, Cobra, Flex, Flumizin e
Pivot de forma isolada ou em mistura, independentemente da época de avaliação.

Aos sete dias após aplicação dos herbicidas (DAAH), verificou-se que as plantas apresentaram maior altura nos tratamentos $\mathrm{T} 1$, T2, T3 e T4, não diferindo estatisticamente $(p<0,001)$ da testemunha (T9). Ao final do período de avaliação foi possível alcançar uma diferença de cerca de $29 \mathrm{~cm}$ entre os tratamentos (Tabela 3). Corroborando com Neto et al. (2009), o uso do isolado de Glyphosate forneceu maior altura de plantas de soja $(100,93 \mathrm{~cm})$, contudo, na mistura com S-metolachlor essa variável foi menor $(70,01 \mathrm{~cm})$. Estes autores afirmaram que a adaptação à competição com plantas vizinhas infestantes, pode promover estiolamento e causar maior altura de planta.

Com base nos resultados referente ao diâmetro do caule (Tabela 4), foram verificadas diferenças estatística entre os tratamentos $(p<0,001)$ e nesta variável os tratamentos $\mathrm{T} 1, \mathrm{~T} 2$, T3 e T4 forneceram resultados superiores aos 
demais tratamentos. Estes resultados evidenciaram efeito positivo quanto aplicação dos herbicidas em sua formulação isolada, independente da sua dosagem. Assim, como foram verificados os mesmos efeitos sobre o número de folhas (Tabela 5). Para Kappes et al.
(2012) o diâmetro do caule é um importante parâmetro morfológico para determinar a suscetibilidade ou resistência da cultura ao acamamento.

Tabela 4. Diâmetro $(\mathrm{mm})$ do caule de feijão-caupi (Vigna unguiculata L. Walp.) em diferentes períodos, após aplicação dos herbicidas (DAAH) para controle de plantas daninhas. Areia (PB), 2017

\begin{tabular}{ccccc}
\hline \multirow{2}{*}{ Tratamentos } & \multicolumn{5}{c}{ Períodos de avaliação } \\
\cline { 2 - 5 } & 7 DAAH & $14 \mathrm{DAAH}$ & $21 \mathrm{DAAH}$ & $28 \mathrm{DAAH}$ \\
\hline T1 & $0,45 \mathrm{aA}$ & $0,53 \mathrm{aA}$ & $0,56 \mathrm{aA}$ & $0,53 \mathrm{aA}$ \\
T2 & $0,50 \mathrm{aA}$ & $0,53 \mathrm{aA}$ & $0,58 \mathrm{aA}$ & $0,63 \mathrm{aA}$ \\
T3 & $0,28 \mathrm{bA}$ & $0,35 \mathrm{aA}$ & $0,39 \mathrm{aA}$ & $0,39 \mathrm{aA}$ \\
T4 & $0,46 \mathrm{aA}$ & $0,48 \mathrm{aA}$ & $0,53 \mathrm{aA}$ & $0,55 \mathrm{aA}$ \\
T5 & $0,20 \mathrm{bA}$ & $0,23 \mathrm{bA}$ & $0,25 \mathrm{bA}$ & $0,27 \mathrm{bA}$ \\
T6 & $0,19 \mathrm{bA}$ & $0,22 \mathrm{bA}$ & $0,23 \mathrm{bA}$ & $0,23 \mathrm{bA}$ \\
T7 & $0,22 \mathrm{bA}$ & $0,23 \mathrm{bA}$ & $0,25 \mathrm{bA}$ & $0,30 \mathrm{bA}$ \\
T8 & ------ & ------ & ----- \\
\hline T9 & $0,44 \mathrm{aA}$ & $0,50 \mathrm{aA}$ & $0,52 \mathrm{aA}$ & $0,58 \mathrm{aA}$ \\
\hline C.V.\% & \multicolumn{5}{c}{52,28} &
\end{tabular}

Médias seguidas de mesma letra minúscula na coluna e maiúscula na linha não se diferenciam estatisticamente pelo teste de Scott-Knott a 5\% de probabilidade. T1=50\% Quizalofope-P-Etílico; T2=50\% Linurom; T3=100 Quizalofope-PEtílico; T4=100\% Linurom; T5=50\% Quizalofope-P-Etílico + 50\% Linurom; T6=50\% Quizalofope-P-Etílico + 100\% Linurom; T7= 100\% Quizalofope-P-Etílico + 50\% Linurom; T8=100\% Quizalofope-P-Etílico + 100\% Linurom e T9= Capina manual.

Para o número de folhas, os tratamentos T1, T2, T3 e T4 apresentaram comportamento parecido na variável referente ao diâmetro do caule, existindo diferença estatística $(p<0,001)$ para os tratamentos (Tabela 5). Bandeira et al. (2016) encontraram resultados similares quanto ao número de folhas da mandioca sob a influência dos tratamentos com haloxyfope, quizalofope-P-etílico e chlorimuronetílico, verficando que não houveram reduções desta variável em relação a testemunha. 
Tabela 5. Número de folhas de feijão-caupi (Vigna unguiculata L. Walp.) em diferentes períodos, após aplicação dos herbicidas (DAAH) para controle de plantas daninhas. Areia (PB), 2017

\begin{tabular}{|c|c|c|c|c|}
\hline \multirow{2}{*}{ Tratamentos } & \multicolumn{4}{|c|}{ Período de avaliação } \\
\hline & $7 \mathrm{DAAH}$ & $14 \mathrm{DAAH}$ & 21 DAAH & 28 DAAH \\
\hline $\mathrm{T} 1$ & $12,00 \mathrm{aA}$ & $15,50 \mathrm{aA}$ & $18,7 \mathrm{aA}$ & $20,32 \mathrm{aA}$ \\
\hline $\mathrm{T} 2$ & $12,33 \mathrm{aA}$ & $16,25 \mathrm{aA}$ & $19,55 \mathrm{aA}$ & $23,07 \mathrm{aA}$ \\
\hline T3 & $7,50 \mathrm{aC}$ & $9,52 \mathrm{bB}$ & $12,93 \mathrm{aA}$ & $13,50 \mathrm{aA}$ \\
\hline $\mathrm{T} 4$ & $10,40 \mathrm{aB}$ & $14,43 \mathrm{aA}$ & $14,83 \mathrm{aA}$ & $18,83 \mathrm{aA}$ \\
\hline T5 & 4,15 bA & $5,43 \mathrm{bA}$ & $7,65 \mathrm{bA}$ & $7,33 \mathrm{bA}$ \\
\hline T6 & $4,43 \mathrm{bA}$ & $5,75 \mathrm{bA}$ & $6,25 \mathrm{bA}$ & $6,33 \mathrm{bA}$ \\
\hline $\mathrm{T7}$ & $4,60 \mathrm{bA}$ & $7,25 \mathrm{bA}$ & $8,50 \mathrm{bA}$ & $9,75 \mathrm{bA}$ \\
\hline $\mathrm{T} 8$ & ------ & ----- & ------ & ------ \\
\hline T9 & 11,75 aA & 15,75 aA & 21,03 aA & 20,40 aA \\
\hline C.V.\% & \multicolumn{4}{|c|}{53,89} \\
\hline
\end{tabular}

Médias seguidas de mesma letra minúscula na coluna e maiúscula na linha não se diferenciam estatisticamente pelo teste de Scott-Knott a 5\% de probabilidade. DAAH = dias após aplicação dos herbicidas. T1=50\% Quizalofope-P-Etílico; T2=50\% Linurom; T3=100 Quizalofope-P-Etílico; T4=100\% Linurom; T5=50\% Quizalofope-P-Etílico + 50\% Linurom; T6=50\% Quizalofope-P-Etílico + 100\% Linurom; T7= 100\% Quizalofope-P-Etílico + 50\% Linurom; T8= 100\% QuizalofopeP-Etílico + 100\% Linurom e T9= Capina manual.

Os resultados estão de acordo com os encontrados por Pessôa et al. (2017), que verificaram números superiores de folhas em plantas de feijão-caupi sob manejo de plantas daninhas com herbicidas (Fenoxaprope-P-etílico, Benzotiadiazinona e Imidazolinona), como também não diferiram do controle mecânico (capina manual). Nota-se que aos 28 DAAH (Tabela 5), apenas os tratamentos T1 e T2 obtiveram os maiores resultados, não diferindo estatisticamente do T9 (testemunha). Aos 28 DAAH o tratamento T2 superou todos os resultados em relação ao número de folha (Tabela 5), já o T6 obteve o menor número de folhas, observado durante período de avaliação, a exceção do tratamento T8.

Os tratamentos T1 e T2 foram considerados insuficientes para promover danos relevantes no desenvolvimento da cultura (Figuras 4, 5 e 6), conforme também foi evidenciado por Fontes et al. (2010), ao verificar que há tolerância dessa mesma cultivar a doses de herbicidas Oxadiazon. Estes resultados também apontam o efeito satisfatório entre as variáveis estudadas (Tabela 3, 4 e 5) com a aplicação do Linurom em sua dosagem máxima (100\%).

Os valores encontrados na análise do controle de plantas daninhas variaram de 4 a 8 , em que foram submetidos aos tratamentos à base de herbicidas (Figura 1). Segundo a escala de notas proposto por EWRC (1964), os resultados da Figura 1, indicam que os tratamentos apresentaram eficiência entre quase forte, média e sem influência na produção. Entretanto, a testemunha (T9) e os tratamentos T1, T2 e T4, apresentaram controle muito leve, notadamente ambos foram aplicados de forma individual. 
Figura 1. Controle de plantas daninhas em plantio de feijão-caupi (Vigna unguiculata L. Walp.) baseado na escala de notas da EWRC (1964).

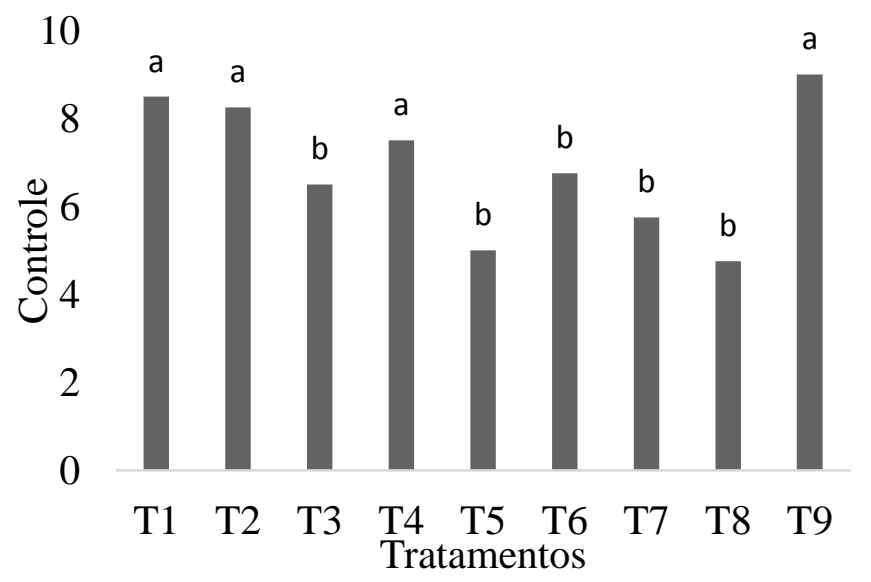

Médias seguidas de mesma letra não se diferenciam estatisticamente pelo teste de Scott-Knott a $5 \%$ de probabilidade. T1=50\% Quizalofope-P-Etílico; T2=50\% Linurom; T3=100 Quizalofope-P-Etílico; T4=100\% Linurom; T5=50\% Quizalofope-P-Etílico + 50\% Linurom; T6=50\% Quizalofope-P-Etílico + 100\% Linurom; T7= 100\% Quizalofope-P-Etílico + 50\% Linurom; T8= 100\% Quizalofope-P-Etílico + 100\% Linurom e T9= Capina manual. Areia (PB), 2017

Verificou-se que o T8 não é indicado no manejo em pós-emergência de plantas de feijãocaupi, por ter provocado a sua morte (Figura 1). Certamente o efeito está ligado a mistura dos herbicidas, quando utilizando a máxima dosagem para ambos. Observou-se um menor controle sobre plantas daninhas quando utilizados os tratamentos T1, T2 e T4, o que pode implicar numa possível resistência dos mesmos em decorrência do uso sucessivo desses produtos em formulações similares. Sizenando Filho et al. (2013) também verificaram efeito parecido dos herbicidas Diuron, Pendimethalin e Metolachlor sobre o feijão-caupi até os 35 DAA.
Com base na Figura 2, observou-se que os tratamentos $\mathrm{T} 1 \mathrm{e}$ T2 apresentaram os menores valores de efeito fitotóxico entre nulo e muito leve (1 a 2), tomando como base a escala de fitotoxidez (EWRC, 1964), assim como a testemunha, que se sobressaiu em relação aos demais tratamentos. Corroborando com Procópio et al. (2003) o s-metolachlor, oriundo da mólecula metolachlor, mostrou-se menos tóxico a apenas uma das seis cultivares de feijão avaliadas. Já Kalsing e Vidal (2013) não verificaram fitotoxidez visual a esse mesmo feijoeiro na fase vegetativa.

Figura 2. Fitotoxidez em plantas de feijão-caupi (Vigna unguiculata L. Walp.) após aplicação de herbicidas em planta daninhas, baseado na escala de notas adaptada de EWRC (1964).

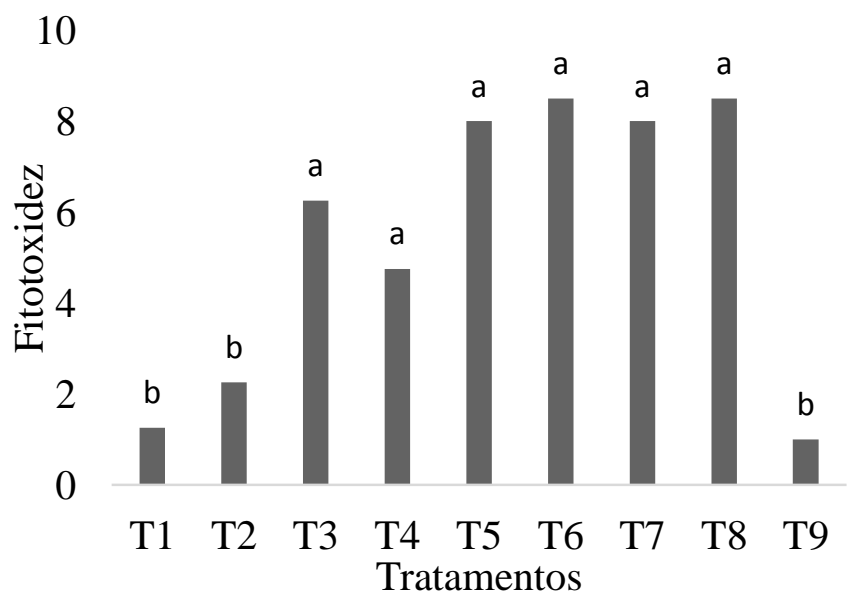

Médias seguidas de mesma letra não se diferenciam estatisticamente pelo teste de Scott-Knott a $5 \%$ de probabilidade. T1=50\% Quizalofope-P-Etílico; T2=50\% Linurom; T3=100 Quizalofope-P-Etílico; T4=100\% Linurom; T5=50\% Quizalofope-P-Etílico + 50\% Linurom; T6=50\% Quizalofope-P-Etílico + 100\% Linurom; T7= 100\% Quizalofope-P-Etílico + 50\% Linurom; T8= 100\% Quizalofope-P-Etílico + 100\% Linurom e T9= Capina manual. Areia (PB), 2017 
Comportamento diferente foi observado para os tratamentos com mistura de herbicidas (T5, T6, T7 e T8), em que foi possível evidenciar o efeito fitotóxico de muito forte a necrose total (Figura 2). Comportamento semelhante de fitotoxidez foi verificado por Cobucci e Wruck (2005), ao utilizarem o Quizalofope-P Etílico. Houve efeito fitotóxico aos sete DAAH, quando foi utilizada a dosagem 1,5 L $\mathrm{ha}^{-1}$, mas perdas na produtividade do feijoeiro não foram observadas. $O$ mesmo foi observado para a cultura do girassol aos 15 DAAH (MACIEL et al., 2002).

\section{CONCLUSÕES}

As plantas de feijão-caupi, cultivar BRS Guariba, apresentam elevada tolerância aos herbicidas Quizalofope-P Etílico e Linurom à 50\% em aplicações pós-emergência.

O herbicida Linurom à $100 \%$ e a formulação do Quizalofope-P Etílico + Linurom provocam danos severos ao desenvolvimento da cultura do feijão-caupi.

A mistura entre os herbicidas à $100 \%$ de Quizalofope-P Etílico e $100 \%$ de Linurom potencializa o efeito dos herbicidas sobre a cultura da feijão-caupi, ocasionando a morte das plantas.

\section{REFERÊNCIAS}

BANDEIRA, H. F. S.; ALVES, J. M.; ROCHA, P. R. R.; STRUCKER, A. TRASSATO, L. B. Tolerância da mandioca a diferentes herbicidas aplicados em pós-emergência. Revista Brasileira de Herbicidas, v.15, n.3, p.241-250, 2016. http://dx.doi.org/10.7824/rbh.v15i3.478

CASTELLETTI, C. H. M.; COSTA, A. F. Feijão-caupi: alternativa sustentável para os sistemas produtivos. Pesquisa Agropecuária Pernambucana, v. 18, p. 1-2, 2013.

CORRÊA, M. J. P.; ALVES, G. L.; ROCHA, L. G. F.; SILVA, M. R. M. Períodos de interferência de plantas daninhas na cultura do feijão caupi. Revista de Ciências Agroambientais, v. 13, n. 2, 2016.

EMBRAPA. Cultivo do feijão-caupi - Sistemas de Produção. 2002. Disponível em: <http://sistemasdeproducao.cnptia.embrapa.br/ FontesHTML/ Feijao/FeijaoCaupi>. Acesso em: 13 mar. 2014. http://dx.doi.org/10.1590/0034$\underline{737 \times 201663010004}$
FONTES, J. R. A.; GONÇALVES, J. R. P.; MORAIS, R. R. Tolerância do feijão-caupi ao herbicida oxadiazon. Pesquisa Agropecuária Tropical, v.40, n.1, p.110-115, 2010. http://dx.doi.org/ 10.5216/pat.v40i1.6241

FREIRE FILHO, F.R. Feijão-caupi no Brasil: produção, melhoramento genético, avanços e desafios. Teresina: Embrapa Meio-Norte, 2011.

FREITAS, F.C.L.; DALLABONA, J.D.; MESQUITA, H.C.; FONTES, L.O. Manejo de plantas daninhas na cultura do feijão-caupi. In: CONGRESSO NACIONAL DE FEIJÃO-CAUPI, 2. Anais... Belém, 2009. Cd-rom.

FROTA, K. M. G; SOARES, R. A.; ARÊAS, M. Composição química do feijão-caupi (Vigna unguiculata L. Walp), cultivar BRS-Milênio. Ciência e Tecnologia de Alimentos, v. 28, n. 2, p. 470-476, 2008. http://dx.doi.org/10.1590/S0101$\underline{20612008000200031}$

KALSING, A.; VIDAL, R. A. Seletividade de herbicidas residuais ao feijão-comum durante o período inicial da fase vegetativa. Planta Daninha, v.31, n.2, p.411-417, 2013. http://dx.doi.org/10.1590/\$0100$\underline{83582013000200019}$

KAPPES, C.; ARF, M. F.; ARF, O.; GITTI, D. C.; FERREIRA, J. P. Resposta da crotalária à épocas e subdoses de aplicação de glifosato. Bioscience Journal, v. 28, n. 3, p. 373-383, 2012.

MACIEL, C. D. G.; CONSTANTIN, J.; OLIVEIRA JR, R. $S$. Controle de plantas daninhas na cultura do girassol com aclonifen aplicado isolado ou em mistura. Revista Brasileira de Herbicidas, v. 3, n. $2 / 3, \quad$ p.117-122, 2002. https://doi.org/10.7824/rbh.v3i2-3.381

MANCUSO, M. A. C.; AIRES, B. C. BEGRISOLI, E.; CORRÊA, M. R.; SORATTO, R. P. Seletividade e eficiência de herbicidas no controle de plantas daninhas na cultura do feijão-caupi. Revista Ceres, v. 63, n. 1, p. 25-32, 2016. http://dx.doi.org/10.1590/0034-

737X201663010004

MESQUITA, H. C.; FREITAS, F. C. L.; FREIRE FILHO, F. R.; SILVA, M. G. O.; CUNHA, J. L. X. L.; RODRIGUES, A. P. M. S. Eficácia e seletividade de 
herbicidas em cultivares de feijão-caupi. Revista Brasileira de Herbicidas, v. 16. n. 1, p. 50-59, 2017. http://dx.doi.org/10.7824/rbh.v16i1.505

NETO, M. E. F.; PITELLI, R. A.; BASILE, E. A. G.; TIMOSSI, P. C. Seletividade de herbicidas pósemergentes aplicados na soja geneticamente modificada. Planta Daninha, v. 27, n. 2, p. 345352, 2009. http://dx.doi.org/10.1590/S0100$\underline{83582009000200018}$

OLIVEIRA, J. R. R. S.; CONSTANTIN, J.; INOUE, M. $\mathrm{H}$. (eds.). Biologia e manejo de plantas daninhas, 2011.

PESSÔA, U. C. M.; OLIVEIRA, K. J. A.; SOUZA, A. S.; PIMENTA, T. A.; MUNIZ, R. V. S.; NETO ARAÚJO, A. G. Desempenho fisiológicos e crescimento do feijão-caupi, sob manejos de plantas daninha. Revista Verde de Agroecologia e Desenvolvimento Sustentável, v. 12, n. 2, p. 246250, 2017. http://dx.doi.org/10.18378/rvads.v12i2.5067

PROCÓPIO, S. O.; SILVA, A. A.; SANTOS, J. B.; RIBEIRO JÚNIOR, J. I. Seletividade do smetolachlor a cultivares de feijão (Phaseolus vulgaris L.). Ciência e Agrotecnologia, v. 27, n. 1, p. 150-157, 2003.2 DOI: http://dx.doi.org/10.1590/S1413$\underline{70542003000100018}$

SALGADO, T. P.; SALLES, M. S.; MARTINS, J. V. F.; ALVES, P. L. C. A. Interferências das plantas daninhas no feijoeiro carioca. Planta Daninha, v. 25, n. 3, p. 443-448, 2007. http://dx.doi.org/10.1590/S010083582007000300002

SILVA, C. O.; GOMES, J. C.; COSTA, N. M. B.; ANDRADE, N. J.; MINIM, V. P. R. Caracterização nutricional de feijão (Phaseolus vulgaris L.) após processamento térmico. Revista Ceres, v. 53, n. 309, p. 528-534, 2006.

SILVA, F. A. S. Assistat-Programa de análises estatísticas, Versão 7.7 beta. Campina Grande: UAEG-CTRN-UFCG, 2012. Disponível em: http://www.assistat.com/index.html. Acesso em: 02 Mar. 2017.

SILVA, J. F.; ALBERTINO, S.M.F. Manejo de plantas daninhas. In: Zilli, J. E.; Vilarinho, A. A.; Alves, J. M. A. A cultura do feijão-caupi na Amazônia brasileira. Boa Vista-RR: Embrapa Roraima, 2009. p. 223-243.

SILVA, M. B. O.; ALVES, P. F. S.; TEIXEIRA, M. F. F.; SILVA, H. D.; SÁ, R. A.; CAMPOS, R. G. C.; CARVALHO, A. J.; ASPIAZÚ, I. Produtividade e componentes de rendimento de feijão-caupi sob efeito de herbicidas aplicados em pósemergência. Unimontes Científica, v. 18, n. 2, p. 76-83, 2016.

SIZENANDO FILHO, F. A.; ALMEIDA, E. I. B.; PINTO, C. M.; PITOMBEIRA, J. B. Seletividade de diferentes herbicidas ao feijão-caupi. Revista Brasileira de Agropecuária Sustentável, v. 3, n. 2, p. 84-90, 2013. http://dx.doi.org/10.21206/rbas.v3i2.222

VILARINHO, A. A. BRS Guariba - cultivar de feijãocaupi de alto desempenho em Roraima. 2007. Artigo em Hypertexto. Disponível em: http://www.infobibos.com/Artigos/2007 4/nova era/index.htm. Acesso em: 28 dez. 2014.

Recebido para publicação em 01/04/2018

Revisado em 23/10/2018

Aceito em 12/11/2018 